\title{
CINECLUBE NA ESCOLA: UMA PROPOSTA SOCIOCULTURAL INTERDISCIPLINAR PARA A PROMOÇÃO DA ALFABETIZAÇÃO CIENTÍFICA
}

\author{
Nádia Ribeiro Amorim¹, Sidnei Quezada Meireles Leite', \\ Vilma Reis Terra ${ }^{3}$, Maria Alice Veiga Ferreira de Souza ${ }^{4}$
}

\author{
Grupo de Pesquisa Educação Científica e Movimento CTSA \\ Programa de Pós-graduação em Educação em Ciências e Matemática \\ Instituto Federal do Espírito Santo - Campus Vitória \\ Avenida Vitória, 1729 - Jucutuquara, Vitória, Espírito Santo. CEP 29040780.
}

\section{RESUMO}

O objetivo desse trabalho foi analisar os aspectos pedagógicos e sociofilosóficos de um cineclube desenvolvido em uma escola de ensino médio, tendo como olhar principal o potencial interdisciplinar e a perspectiva sociocultural dessa atividade pedagógica. Esse projeto de extensão escolar envolveu alunos do ensino médio, aluno de graduação como monitor, professores da educação básica e pesquisadores da área de Educação em Ciências. A pesquisa qualitativa, teórica-empírica, foi desenvolvida na perspectiva de um estudo de caso, a partir de observações, aplicação de entrevistas semiestruturadas e análise de documentos oficiais. Os aspectos pedagógicos e sociofilosóficos foram discutidos a partir da exibição do filme Erin Brockovich: uma mulher de talentos. Os resultados evidenciaram a promoção de debates sobre ciência articulados à temas socioambientais e interdisciplinares, se constituindo como sendo um espaço interdisciplinar de alfabetização científica.

Palavras-chave: alfabetização científica. interdisciplinaridade. cineclube escolar. educação em ciências.

\section{ABSTRACT}

The aim of this study was to analyze the sociophilosofical and pedagogical aspects of a cineclub and developed into a state high school, foccusing on the potential interdisciplinary and sociocultural look. This project involved the extension school, high school students, undergraduate student as a monitor, basic education teachers and researchers in the field of Science Education. Qualitative research, theoretical and empirical, has been developed in view of a case study, from observations, application of semi-structured interviews and analysis of official documents. Ten films were shown, followed by discussion guided by social and environmental issues. The sociophilosofical and pedagogical aspects were discussed from the screening of the film Erin Brockovich, a woman of talent. The results showed the promotion of science debates on the themes, constituting as a space for interdisciplinary scientific literacy.

Keywords: scientific literacy. interdisciplinary. school cineclub. science education.

1Professora de Química da Rede Estadual de Educação Básica do Espírito Santo. Mestranda do Membro do Programa de Pósgraduação em Educação em Ciências e Matemática do Ifes. E-mail: nranadia@gmail.com.

2 Professor de Educação em Ciências e Química do Instituto Federal do Espírito Santo, D.Sc. Membro permanente do Programa de Pós-graduação em Educação em Ciências e Matemática do Ifes. E-mail: squezada@ifes.edu.br.

3 Professora de Química do Instituto Federal do Espírito Santo, D.Sc. Membra permanente do Programa de Pós-graduação em Educação em Ciências e Matemática do Ifes. E-mail: terravilma@gmail.com.

4 Professora de Matemática do Instituto Federal do Espírito Santo, D.Ed. Membra permanente do Programa de Pós-graduação em Educação em Ciências e Matemática do Ifes. E-mail: alicevfs@hotmail.com. 


\section{INTRODUÇÃO}

O ensino de ciências (Biologia, Química e Física) está marcado pelo conteudismo, memorização excessiva, descontextualização e ausência de interdisciplinaridade. Segundo Teixeira (2003, p. 178), “a ciência que é ensinada nas escolas, sustenta uma imagem idealizada e distante da realidade do trabalho dos cientistas, omitindo antagonismos, conflitos e lutas que são travadas por grupos responsáveis pelo progresso científico". Nesse modo de ensino, os alunos são espectadores, ou seja, não possuem ou, quando possuem, é mínima a participação ativa na construção de seu conhecimento.

Segundo FOUREZ (2003, p. 110), há uma crise no ensino de ciências que possui como sujeitos principais "os alunos, professores de ciências, os dirigentes da economia, os pais, os cidadãos (trabalhadores manuais ou outros) etc". Ele faz, ainda, um comentário sobre a participação dos alunos e professores nessa crise. Segundo ele, os alunos "não estão preparados para se engajar em estudos científicos. Sua admiração pelos cientistas conduz os jovens a felicitá-los pelo seu maravilhoso trabalho, e nada mais..." (2003, p. 110). É possível que a falta de engajamento dos alunos, mencionada por Fourez, esteja baseada em aspectos ligados a método, o que aumenta a importância de se experimentar novas abordagens.

De acordo com ARROIO (2006, p. 173), carreiras como física, química e matemática, por não serem tão valorizadas como medicina, direito e engenharia, não despertam interesse nos jovens. E para tentar mudar essa visão ele elaborou o projeto "Show de Química”. Visto que, segundo ele "a experimentação desperta interesse entre os alunos, independente do nível de escolarização".

Na tentativa de promover mudança real no método de ensino, nos baseamos na teoria de Vygotsky, pois enfatiza que "[...] a cultura e a interação social estão envolvidas no desenvolvimento da consciência humana" (LEFRANÇOIS, 2008, p. 266). Para ele, o professor deve levar em conta a cultura, a linguagem e a interação social de seus alunos. Segundo Lefrançois (2008, p. 266), “o tema singular mais importante de Vygotsky pode ser resumido em uma frase: a interação social está fundamentalmente envolvida no desenvolvimento da cognição." Por interação social entende-se interação cultural, ou seja, a cultura e a maneira como cada aluno se relaciona na sociedade é essencial para seu desenvolvimento cognitivo. Além disso, deve-se levar em conta a Zona de Desenvolvimento Proximal (ZDP) de cada aluno, que, segundo Davydov, seria: "O que a criança inicialmente consegue fazer apenas junto com 
adultos e seus iguais, e na sequencia o faz de forma independente" (LEFRANÇOIS, 2008, p. 269).

A tarefa, então, dos pais e dos professores seria propiciar atividades adequadas para cada aluno, ou seja, nem difíceis a ponto de não conseguirem realizá-las e nem tão fácil a ponto de não representarem qualquer dificuldade.

Levando em conta as ideias de Vygotsky, e no intuito de tornarmos as aulas mais "palatáveis" para os alunos, propusemos a utilização de material lúdico, pois este pode vir a proporcionar maior efetividade ao ensino de ciências, por meio de conexões entre as ciências e o cotidiano. É como pensa YAMAZAKI (2006) ao constatar, após um levantamento sobre a utilização desse método em inúmeras instituições de ensino, que a utilização de metodologias alternativas propõe uma significante mudança na prática de professores que pretendem, de fato, ensinar ciências; não é por acaso que o uso de métodos tradicionais é considerado por muitos alunos entediante, maçante e pouco proveitoso.

Sobre o uso de cinema na escola, DUARTE (2002) afirma que esta relação ocorre há muitas décadas, embora não se reconheçam como parceiros na formação geral das pessoas. Ainda segundo Duarte, os chamados "filmes de escola" propiciam bons debates sobre os problemas que enfrentamos no dia-a-dia da atividade educacional. Entretanto, a mesma autora ressalta que para obter uma atividade produtiva é necessário verificar a qualidade do filme pretendido, pesquisar outros filmes do mesmo gênero e gerar um roteiro de discussão condizente com o assunto que se deseja trabalhar.

0 uso de filmes na escola, se planejado, nos permite trabalhar de maneira eficaz temas interdisciplinares como alimentação, tecnologia, ética, saúde, entre outros. Um dos maiores pesquisadores dessa área, Gusdorf, em carta escrita à Fazenda (2002, p.24) discorre sobre interdisciplinaridade:

o que se designa por indisciplinaridade é uma atitude epistemológica que ultrapassa os hábitos intelectuais estabelecidos ou mesmo os programas de ensino. Nossos contemporâneos estão sendo formados sob um regime de especialização, cada um em seu pequeno esconderijo, abrigado das interferências dos vizinhos, na segurança e no conforto das mesmas questões estéreis. Cada um por si e Deus por todos (...). 
Fazenda (2002, p.31) discute que para ocorrer a interdisciplinaridade deve-se haver uma mudança de postura em relação ao conhecimento: “a substituição de uma concepção fragmentada pela unitária do ser humano". Trabalhando de forma interdisciplinar, os alunos conseguem assimilar, com maior facilidade, assuntos complexos como alimentos transgênicos, desenvolvimento de novas tecnologias, a contribuição da tecnologia para a obesidade, etc. Assim, podemos tornar o processo de alfabetização científica mais agradável. 0 citado termo "Alfabetização Científica" refere-se, segundo Chassot (2003) ao fato de a ciência ser considerada uma linguagem e, deve, portanto, ser entendida por todos. Concordamos com esse autor quando afirma que "ser alfabetizado cientificamente é saber ler a linguagem em que está escrita a natureza. É um analfabeto científico aquele incapaz de uma leitura do universo" (CHASSOT, 2003, p. 91).

Com uma proposta de ensino que privilegia as interações socioculturais dos sujeitos e fazendo uso da interdisciplinaridade, esse projeto extraclasse tem como principal objetivo a promoção da alfabetização científica em alunos de ensino médio de escolas de rede pública de ensino, por meio de método alternativo.

\section{PROCEDIMENTOS METODOLÓGICOS}

0 estudo foi realizado entre o segundo semestre de 2011 e primeiro semestre de 2012, na Escola Estadual de Ensino Fundamental e Médio Jacaraípe, localizada no município de Serra/ES, em parceria com o Instituto Federal do Espírito Santo - IFES. Participaram 15 alunos do ensino médio do turno matutino dessa escola que aceitaram espontaneamente o convite dirigido a todos desse turno.

A pesquisa caracteriza-se como qualitativa, que, segundo Demo (1998, p. 101) “dedica-se mais a aspectos qualitativos da realidade, ou seja, olha prioritariamente para eles, sem desprezar os aspectos também quantitativos. E vice-versa." Seguindo essa metodologia trabalhamos com observação participante e realizamos entrevistas semiestruturadas e análise de documentos.

Após a organização do grupo de trabalho foi discutida a escolha dos filmes que seriam exibidos e os assuntos a serem trabalhados. Os dados foram coletados por meio de entrevista semi-estruturada e questionários (FIGURA 1) realizados com os sujeitos e, posteriormente, analisados, segundo a técnica de análise de conteúdo de BARDIN (2011). 
Foram exibidos dez filmes (QUADRO 1) ao todo. Para cada filme foram selecionados alguns assuntos.
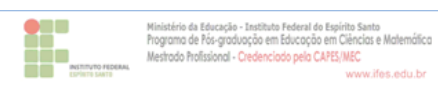

Questionário 2 - Alunos

Projeto de Mestrado

"ALFABETIZACẢO CIENTIFICA NO CINECLUBE IEDIO DO ESPIRTTO SANTO: ESPACO EXTRACLASSE DE ENSINO DE CIÉNCLAS E

Pesquisadora: NÁDIA RIBEIRO AMORIM Orientadora: Prof. $\mathrm{Dr}^{2}$. Maria Alice V. F. de Souza

Orientadora: Prof". Dra ${ }^{2}$. Vilma Reis Terra

ANÁLISE APOS O FILME Erin Brockoxich:

OBJETTV: Uma mulher de talento

Este questionánio é parte do trabalho de pesquisa da pesquisadora Nádia Ribeiro Amorim e se destina a coletar dados para sua Dissertação, cujo objetivo Escola" em escolas públicas estaduais com vistas identificar indícios da promoçãa da alfabetização científica, conexão dos saberes Interdisciplinaridade.

Data:

Nome:

Série: Turma: Idade: anos

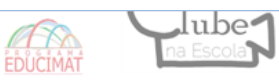

1) Você conhece ou já assistiu ao filme Erin Brockoxich: uma mulher de talento?

Sim ( ) Não ( )

2) Você gostou do filme exibido?

$\operatorname{Sim}$ (W) Não ( )

8) O conteúdo discutido ficou mais "claro" após

$\operatorname{Sim}(\omega)$ Não()

$\operatorname{Sim}$ () Não( )

3) Há algum(uns) assunto(s) discutidos durante o mais chamou(aram) atençı? Qual(ais)?

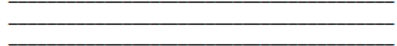

4) Essa exibição no "Cineclube" na Escola:

()) Superou minhas expectativas

(w) Foi o que eu esperava

( ) Não foi o que eu esperava

5) Você voltará para a próxima exibição?

$\operatorname{Sim}($ )

Não( )

6) Você gostou da aula prática?

Sim () Não ( )

7) Você considera importante ter aula prática?

FIGURA 1. Questionário utilizado após a exibição do 3ํ filme 


\begin{tabular}{|c|c|c|c|c|c|}
\hline Exibição & Filme & $\begin{array}{l}\text { Possíveis } \\
\text { discussões }\end{array}$ & Exibição & Filme & $\begin{array}{c}\text { Possíveis } \\
\text { discussões }\end{array}$ \\
\hline $1^{\mathrm{o}}$ & $\begin{array}{c}\text { Wall-E } \\
(02 / 05 / 12)\end{array}$ & $\begin{array}{l}\text { Uso Excessivo da } \\
\text { tecnologia, } \\
\text { obesidade, explosão } \\
\text { demográfica, cálculo } \\
\text { de IMC, cálculo do } \\
\text { valor energético dos } \\
\text { alimentos, leitura } \\
\text { crítica de rótulos dos } \\
\text { alimentos. }\end{array}$ & $6^{0}$ & $\begin{array}{c}\text { O óleo de } \\
\text { Lorenzo } \\
(06 / 06 / 12)\end{array}$ & $\begin{array}{c}\text { Síntese de } \\
\text { remédios, } \\
\text { perseverança, } \\
\text { opinião crítica, } \\
\text { doenças } \\
\text { degenerativas. }\end{array}$ \\
\hline $2^{o}$ & $\begin{array}{c}\text { Apollo } 13 \\
(09 / 05 / 12)\end{array}$ & $\begin{array}{c}\text { Tecnologias que } \\
\text { surgiram após a ida } \\
\text { do homem à Lua, } \\
\text { utilização e função } \\
\text { dos conservantes } \\
\text { naturais e artificiais. }\end{array}$ & $7^{\circ}$ & $\begin{array}{c}\text { O dia depois de } \\
\text { amanhã } \\
(13 / 06 / 12)\end{array}$ & $\begin{array}{c}\text { Mudanças } \\
\text { climáticas: } \\
\text { causas e } \\
\text { consequências, } \\
\text { verdades e mitos } \\
\text { sobre esse filme. }\end{array}$ \\
\hline $3^{\circ}$ & $\begin{array}{c}\text { Erin } \\
\text { Brockovich: } \\
\text { Uma mulher } \\
\text { de talento } \\
(16 / 05 / 12)\end{array}$ & $\begin{array}{l}\text { Importância da } \\
\text { alfabetização } \\
\text { científica, ética, } \\
\text { utilização do cromo } \\
\text { VI e III, toxicologia } \\
\text { desse elemento. }\end{array}$ & $8^{\circ}$ & $\begin{array}{c}\text { Lixo } \\
\text { Extraordinário } \\
(20 / 06 / 12)\end{array}$ & $\begin{array}{c}\text { Utilização de } \\
\text { material } \\
\text { reciclado, } \\
\text { condições de } \\
\text { trabalho, } \\
\text { importância do } \\
\text { estudo, produção } \\
\text { de sabão a partir } \\
\text { de óleo usado. } \\
\end{array}$ \\
\hline 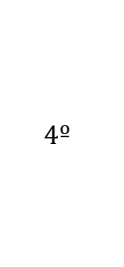 & $\begin{array}{c}\text { O Jardineiro } \\
\text { Fiel } \\
(23 / 05 / 12)\end{array}$ & $\begin{array}{c}\text { Processos de criação } \\
\text { de remédios, leitura } \\
\text { de bula de remédios, } \\
\text { corrupção em países } \\
\text { subdesenvolvidos, } \\
\text { ignorância da } \\
\text { população desses } \\
\text { países. }\end{array}$ & 9음 & $\begin{array}{l}\text { O Código Da } \\
\text { Vince } \\
(27 / 06 / 12)\end{array}$ & $\begin{array}{l}\text { Química no } \\
\text { cotidiano, } \\
\text { utilização de } \\
\text { símbolos. }\end{array}$ \\
\hline $5^{\mathrm{o}}$ & $\begin{array}{l}\text { A Lista de } \\
\text { Schindler } \\
(30 / 05 / 12)\end{array}$ & $\begin{array}{c}\text { Ética, causas do } \\
\text { holocausto, Primeira } \\
\text { e Segunda Guerras } \\
\text { Mundiais, problemas } \\
\text { relacionados à falta } \\
\text { de higiene em seres } \\
\text { humanos. }\end{array}$ & $10^{\circ} \mathrm{o}$ & $\begin{array}{c}\text { Anjos e } \\
\text { Demônios } \\
(04 / 07 / 12)\end{array}$ & $\begin{array}{c}\text { Surgimento de } \\
\text { novas } \\
\text { tecnologias e } \\
\text { suas aplicações: } \\
\text { acelerador de } \\
\text { partículas (LHC), } \\
\text { RMN. }\end{array}$ \\
\hline
\end{tabular}

QUADR0 1. Cronograma do Cineclube na escola com os assuntos discutidos

\section{RESULTADOS E DISCUSSÃO}

Esses assuntos foram escolhidos pela professora de química, pois a mesma conhece o déficit de seus alunos. Contudo, para cada exibição foi entregue uma apostila (FIGURA 2) contendo algumas informações pertinentes, e essa apostila foi montada por alunos bolsistas de Iniciação Científica Júnior (o projeto é financiado pelo Fundo de Apoio a Pesquisa do Espírito Santo - FAPES). Esse já foi um grande ganho, pois esses alunos puderam definir quais assuntos queriam discutir. É importante deixar claro que a professora não interferiu em nenhuma escolha feita pelos mesmos. 

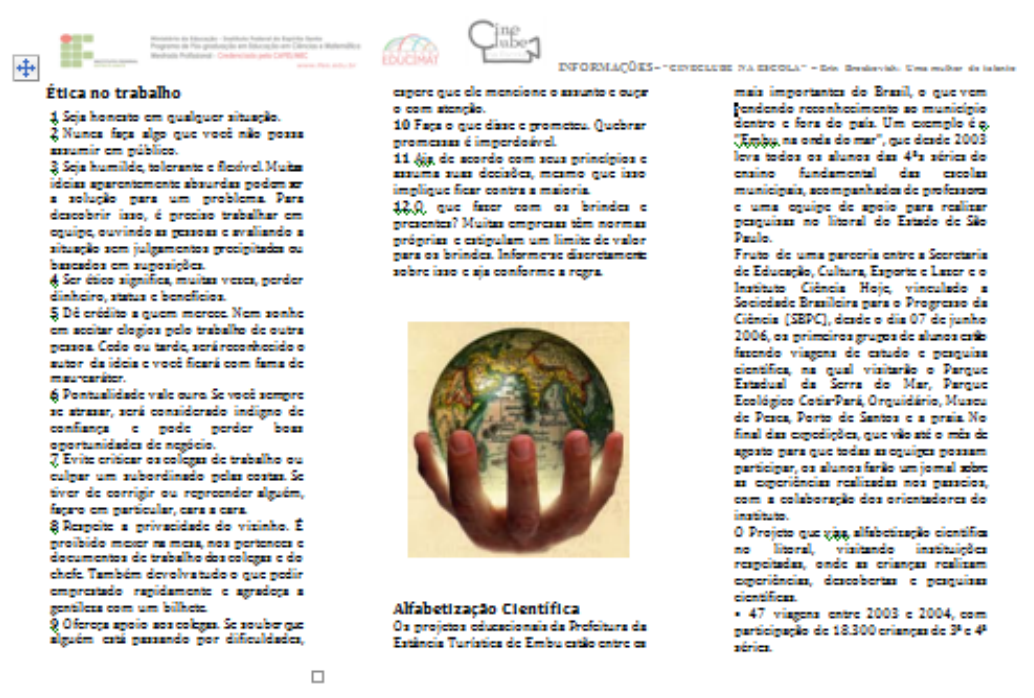

FIGURA 2. Apostila utilizada no debate do filme Erin Brockovich: uma mulher de talento.

Durante os debates os alunos puderam falar livremente sobre os assuntos que achavam pertinentes e também tirar suas dúvidas. A professora só interferia quando percebia que seus alunos estavam se abstraindo.

A maneira como foi tratado o debate e a escolha dos experimentos está de acordo com a teoria cognitiva de Vygotsky (LEFRANÇOIS, 2008), pois privilegia a interação entre os alunos e entre estes e a professora. Houve certa aproximação entre estas partes. Ouve um momento em que alguns alunos comentaram: "nossa professora, você é totalmente diferente do que nós pensávamos."; "tínhamos medo de você."; "você é sempre tão séria e aqui nós podemos conversar sem problemas... você não está preocupada em "passar" matéria".

A professora ficou um pouco chocada em ouvir tais comentários, mas ficou feliz, pois percebeu que havia permitido a aproximação dos alunos e que eles iriam participar ativamente das atividades sem qualquer medo. E foi o que aconteceu durante todos os encontros. Essa professora percebeu o quanto essa interação com seus alunos é importante.

Devemos analisar também os conteúdos abordados e a maneira como estes foram trabalhados, visto que é daí que surge a interdisciplinaridade e a alfabetização científica. 
Peguemos como exemplo a exibição do terceiro filme: Erin Brockovich: uma mulher de talento. Percebi a maneira atenciosa como os alunos assistiram a esse filme e percebi, durante o debate, que eles haviam se identificado com a atriz principal, Julia Roberts. Eles perceberam a maneira como ela falava, suas roupas e seus problemas financeiros.

A partir dessas observações iniciou-se o debate que trouxe temas como a ética, importância da alfabetização científica, utilização e toxicologia do cromo 0, III e VI.

Foi discutido com eles o conceito de ética, ética no trabalho (esses alunos já trabalharam ou estão trabalhando), o que vem a ser alfabetização científica (foi utilizado o conceito de Chassot, já apresentado neste artigo), a importância de ser alfabetizado, a utilização do cromo e a toxicologia das três espécies mais abundantes (0, III e VI).

Ao final a professora fez as seguintes perguntas aos alunos:

"Vocês consideram importante saber fazer a leitura do universo?"

Uma aluna respondeu:

"Claro professora, se aquelas pessoas conhecessem alguma coisa sobre o cromo não teriam sido enganadas".

Uma outra pergunta interessante foi:

"Vocês sabem qual a espécie de cromo é mais nociva?"

Em couro ouviu-se a resposta:

“O cromo VI!"

A partir dessas respostas podemos perceber que esses alunos absorveram as informações passadas. Eles conseguiram compreender a importância do conhecimento científico e a necessidade de transpô-lo para seu cotidiano. Essa é uma das definições de alfabetização científica encontrada em um dos trabalho de Durant (2005, p. 22): "Ela vai além da ciência como conhecimento e da ciência como um processo idealizado, levando em conta a ciência como uma prática social."

Para finalizar esse encontro a professora propôs a construção de um bafômetro (FIGURA 3 e 4). Os alunos ficaram empolgados e logo se levantaram para a prática. Todos participaram e um detalhe que deve ser divulgado foi a motivação percebida nesses alunos durante a execução do experimento proposto (FIGURAS 5 e 6). 

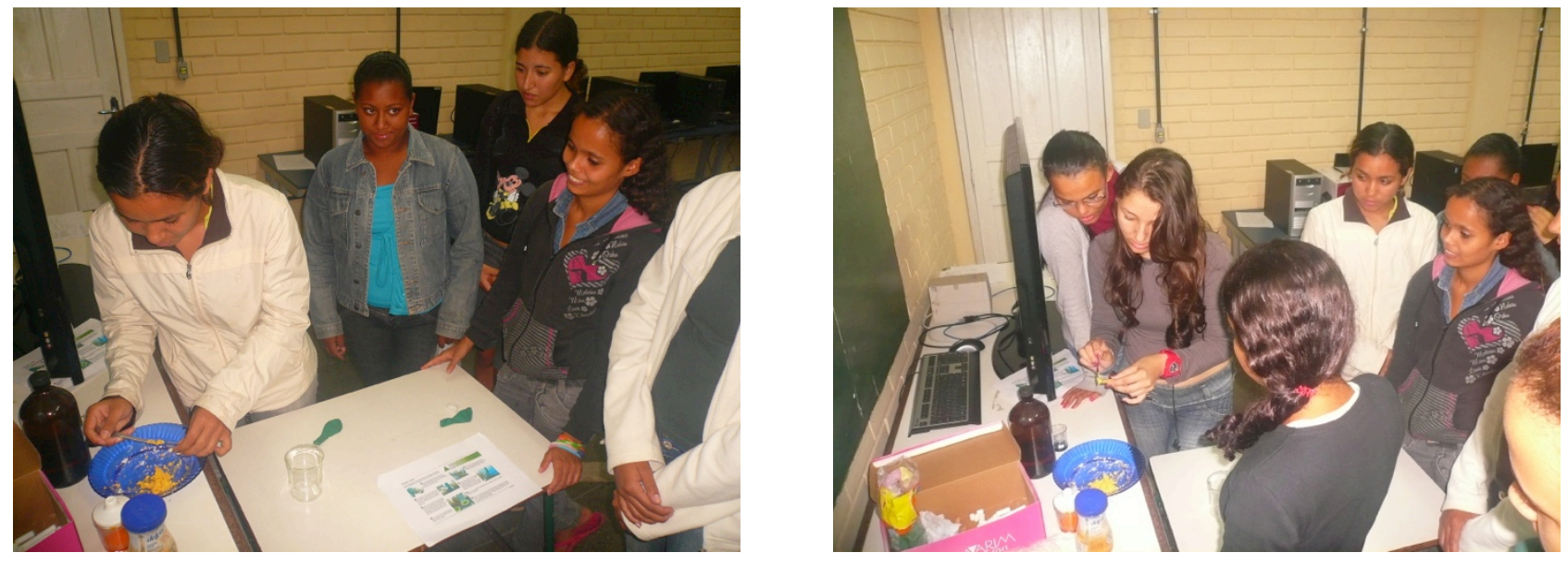

FIGURAS 3 e 4. Alunos construindo o bafômetro
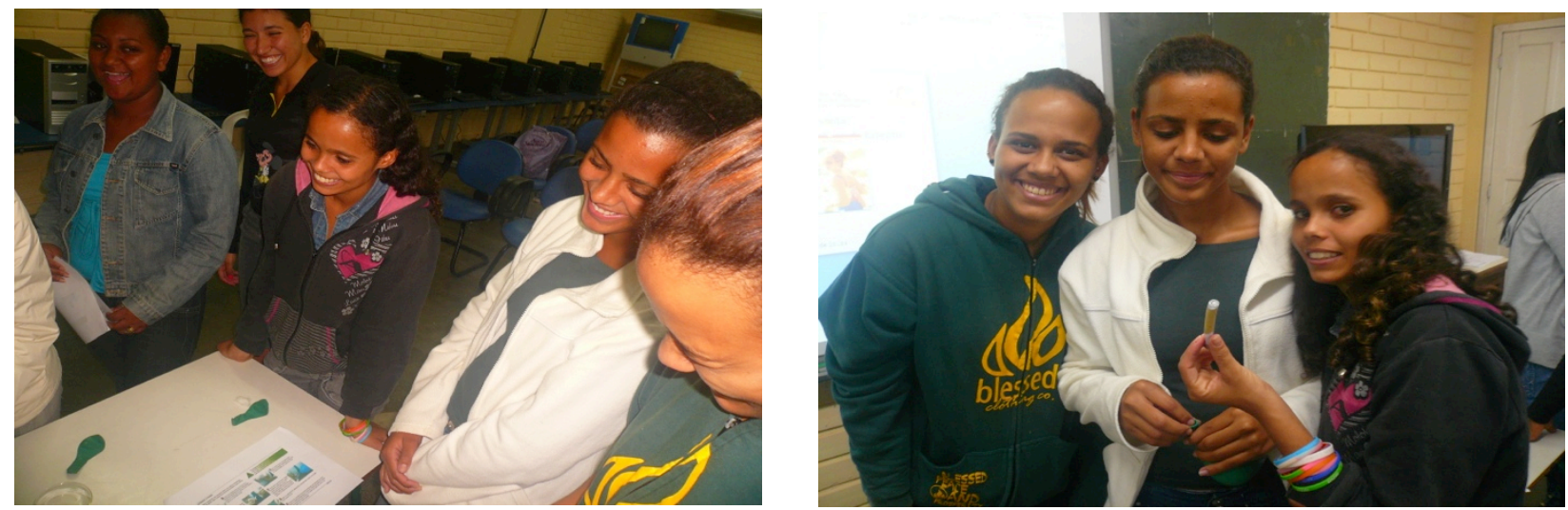

FIGURAS 5 e 6. Motivação dos alunos em realizarem uma aula prática 


\section{CONSIDERAÇÕES FINAIS}

A partir de uma metodologia diferenciada com a utilização de material lúdico os alunos demonstraram um interesse, geralmente, incomum em relação à obtenção de conhecimento. A metodologia utilizada, baseada na teoria sociocultural de Vygotsky e aliada á interdisciplinaridade, facilitou a absorção desse conhecimento. Essa prática também possibilitou a aproximação dos alunos com a professora, garantindo assim uma participação mais ativa durante o debate e a aula prática. 0 comportamento, bem como as respostas dadas à professora, nos mostra que a implantação dessa metodologia diferenciada torna viável a alfabetização científica em escolas onde há escassos recursos didáticos e professores com poucas horas de planejamento.

\section{AGRADECIMENTOS}

Os autores agradecem à FAPES pelo apoio financeiro, aos alunos participantes e à direção da escola pública por ter nos permitido a realização desse projeto.

\section{REFERÊNCIAS}

ARROIO, A, et. al. O Show da Química: motivando o interesse científico. Química Nova, Vol. 29, No. 1, 173-178, 2006, p. 173.

BARDIN, L. Análise de conteúdo. São Paulo: Edições 70, 2011.

CHASSOT, A. Alfabetização científica: uma possibilidade para a inclusão social. Revista Brasileira de Educação. no 22, 2003, p. 91.

DUARTE, R.; Ciência \& Educação. Belo Horizonte: Autêntica, 2002. - 2 ed.

DEMO, P.; Pesquisa Qualitativa busca de equilíbrio entre forma e conteúdo. Rev.latinoam.enfermagem, Ribeirão Preto, v. 6, n. 2, p. 89-104, abril 1998, p. 101.

DURANT, J. 0 que é alfabetização científica? In: Terra Incógnita a interface entre ciência e público. Casa da Ciência, UFRJ. 2005, p. 22. 
FAZENDA, I. C. A. Interdisciplinaridade um projeto em parceria. Edições Loyola. São Paulo. 2002, p. 24, 31.

FOUREZ, G.; Crise no ensino de ciências? Investigações em Ensino de Ciências - v. 8, pp. 109123, 2003. p. 110.

LEFRANÇOIS, G. R. Teorias da Aprendizagem. Cengage Learning. São Paulo, 2008, p. 266, 269.

TEIXEIRA, P. M. M. A educação científica sob a perspectiva da pedagogia histórico-crítica e do movimento c.t.s. no ensino de ciências. Ciência \& Educação, v.9, n. 2, p. 177-190, 2003. p. 178.

YAMAZAKI, S. C.; YAMAZAKI, R. M. O.; Sobre o uso de metodologias alternativas para ensino-aprendizagem de ciências. Educação e Diversidade na Sociedade Contemporânea. Ed. Coelho, 2006. 